\title{
On the Trading Platform Mode of Cross-border E-commerce in China
}

\author{
Wuge Li \\ Xi'an International University, Xi'an Shaanxi, 710077 \\ hunter2011@foxmail.com
}

Keywords: Cross-border e-commerce, Trading platform, The status quo and suggestions Foreword

\begin{abstract}
In recent years, cross-border e-commerce has been developing rapidly in China and has gradually become a new trend for China's national trading development and the new benchmark of national economy. Trading platform is designed to promote further development of cross-border e-commerce. This paper first describes the meaning and status of cross-border e-commerce trading platform, then analyzes types of cross-border e-commerce trading platforms in China and finally puts forward some constructive opinions on the basis of the status quo. The author hopes that this paper can help to promote the construction and development of cross-border e-commerce trading platforms in China.
\end{abstract}

\section{Introduction}

Alibaba, DHgate and Global Information are three well-known enterprises in China cross-border e-commerce trading chain and have been playing a positive role in promoting construction of cross-border e-commerce trading platform. Cross-border e-commerce trading platform not only combines multi-level professional services like international business payments, logistics and transportation and commercial credit cooperation, but is more sensitive to local laws and regulations, cultural traditions and residents' living habits, allowing more enterprises and foreign investors to enter China and providing more opportunities for the development of small and medium-sized enterprises.

\section{Meaning and Development Status of Cross-border E-commerce Trading Platform}

Core Meaning of Cross-border E-commerce Trading Platform. As the term indicates, cross-border e-commerce trading platform refers to a virtual environment where economic trading units in different regions or countries communicate and develop business information and finish project negotiation and payment. As an internationalized platform with high flexibility, low cost and high efficiency, it greatly improves monetary transmission efficiency in international trade and thus makes it possible for many SMEs to realize multinational development like large enterprises, reducing the competitive gap between large enterprises and SMEs. Cross-border e-commerce is established on the basis of Internet technology and generally constrained by network factors and trading subject. Behaviors and values of cross-border trading subjects are different with traditional trading forms; considering that too many processes are involved in cross-border trading, the adoption of cross-border e-commerce trading platform can help reduce the difficulties in trading, but also provide certain information advice for them, which is also currently the main channel for foreign trade enterprises and individual businesses to carry out cross-border trading.

Development Status of Cross-border E-commerce Trading Platform. Since the twenty-first century came, e-commerce industry in China has been developing rapidly and the emergence of cross-border e-commerce trading platform promoted the development of cross-border trading further, making many enterprises and private businesses aware of the investment highlights in cross-border trading. Since the beginning of 2008, many cross-border e-commerce trading platforms in China have been favored by investment companies and many enterprises have received a total of nearly $\$ 5$ billion investment. In June 6, 2013, Orchid Pavilion succeeded in being listed on the New York Stock Exchange Center and became the first cross-border e-commerce foreign 
trade platform in China being listed on foreign stock market, with the first financing amount reaching \$ 83.2 million.

Under such a positive prospects of cross-border e-commerce trading in China, besides the existing cross-border e-commerce trade platforms, the National Development and Reform Commission and the General Administration of Customs have started pilot cross-border trade e-commerce services in seven cities in China and at the same time established distinctive cross-border e-commerce trading platforms. The pilot cities are as follows:

1, Shanghai Free Trade Zone.

2, Chongqing four cross-border trade business.

3, Ningbo cross-border trade e-commerce platform.

4, Zhengzhou Airport Economic Experimental Zone.

Besides the existing cross-border e-commerce trading platform and the emerging cross-border e-commerce trading experimental areas, some traditional large e-commerce enterprises are also increasingly recognizing the importance of cross-border e-commerce trading platform and flocking into the industry. For example, some well-known e-commerce platforms like Tmall International, Suning Tesco and Eslite are beginning to develop towards cross-border e-commerce trading platforms and gradually expend international market. The author believes that in the future, competition between cross-border e-commerce trade platforms will be fiercer.

\section{Working Platform of Existing Cross-border E-commerce Trading Platforms in China}

Since 2004, cross-border e-commerce trading in China has grown stronger and the rapid development of the industry promotes the emergence of high-integrated cross-border e-commerce trading platforms providing rapid transaction, payment and logistics and the formation of a very mature trading chain and the gradual presentation of a clear business mode. According to the function and position of cross-border e-commerce trading platforms in trading environment, cross-border e-commerce trading platforms can be classified into four types: traditional cross-border block trading platform, or B2B model; comprehensive cross-border small wholesale and retail platform, which can also be called B2B or C2C; vertical cross-border small wholesale and retail platform, namely B2C; third-party cross-border services platform or agent of operation.

Most Traditional Cross-border Block Trading Platform. Traditional cross-border block trading platform mainly refers to the online e-commerce trading platform providing import and export trade services in China mainly for domestic and international member companies, allowing them to conduct business transactions on the platform and promoting bilateral transactions.

Comprehensive Cross-border Small Wholesale and Retail Platform. Comprehensive cross-border small wholesale and retail platform mainly refers to that domestic enterprises and private businessmen reach agreements on the Internet by third party cross-border e-commerce platforms, mainly between sellers and buyers in different areas or countries. No declaration or customs duties should be paid in the transaction process, but the trade platform does not involve payments of logistics or assets itself, that is the emerging e-commerce technology on the basis of traditional small cross-border trade.

Vertical Cross-border Small Wholesale and Retail Platform. Vertical cross-border small wholesale and retail platform mainly refers to that private businessmen contact suppliers of goods themselves, buy goods source and then sell them on their own cross-border e-commerce trading platform to foreign countries. This platform can provide buyers information consultation, logistics, payment, customer services and other relevant services; simply speaking, private businessmen connect goods manufacturing plants in the one end and foreign consumer groups in the other end and earn the difference by trading and selling.

Professional Third-party Service Platform. Professional third-party service platform will not generate from trading and transactions directly and indirectly and its main working content in the process of goods circulation is to provide some small-scale cross-border wholesale and retail businessmen with optimal solutions of cross-border trading and help them to solve problems like background payment, logistics options, customer services and regulations, helping some small 
businessmen to enter cross-border e-commerce trading platform and obtain certain economic benefits.

\section{Problems and Optimization Measures in the Establishment of China's cross-border e-commerce trading platform}

Lack of Industry Chain and In-depth Integration. Compared with traditional international trading forms, cross-border e-commerce trade is characterized by multi-facets, small amount, high frequency, information and digitalization; their own channel and platform have certain advantages and own absolutely key position in the industry chain; by optimize and adjust the relationship between multi-sectors can the whole industry chain be activated, promoting the development of relevant enterprises and the restructuring of some small and medium-sized enterprises.

Failure in identifying accurately the operation trend of industry chain is the main reason for uncompetitiveness of cross-border e-commerce trading platforms; in addition, interference of factors like logistics, arrival speed and customer services will directly affect the buyer's shopping experience. Therefore, cross-border e-commerce trading platform should integrate the operation of industry chain and enterprises into a larger operating system and accurately analyze all types of hot-selling products and the selling amounts of products. In addition, "overseas warehouse" model can also be adopted so that once buyers place an order that goods can be directly delivered from the local storage into the buyers'; it can reduce the transportation cost of individual items and at the same time improve business-to-control force of goods, facilitating the treatment of late trade disputes or return of goods.

Severe Service Homogenization Phenomenon. Cross-border e-commerce owns very large development space, both in domestic and foreign market, and many well-known e-commerce enterprises begin to participate in the industry. At present, cross-border e-commerce trading platforms in China are still mainly traditional marketing business, which lacks deepened integration and personalized service and cannot meet the transforming needs of domestic platforms from "plants" to "malls".

"Made in China" is still an inexpensive add-on product in the eyes of domestic and foreign buyers and lacks position and competitiveness in overseas market. Therefore, construction of cross-border e-commerce trading platforms should be started from suppliers to improve the selection indicators of businessmen and goods so as to improve the core competitiveness of goods by comparison of goods quality. With the emergence and popularization of mobile shopping, cross-border e-commerce trading platforms should be connected to mobile shopping; online and offline integration of mobile shopping should be strengthened. For example, overseas off-line experience store can be established to eliminate the overseas users' crisis of confidence in the goods so as to narrow the distance between buyers and sellers. In addition, in the process of localization operations, buyers should be provided with local payment means to improve buyers' consumption experience and payment sense and at the same time promoting the differentiated development of cross-border e-commerce trading platforms.

Increasing Difficulties in Protecting Intellectual Property Rights. Compared with traditional foreign trade mode, shipping channels of cross-border e-commerce trading platform are relatively complex and there are also too many commodity types and brands; therefore, workload and difficulties of customs department in determining the intellectual property rights of products increases greatly. Due to the multifaceted feature of cross-border e-commerce trade and the fact that laws and regulations in different countries or regions are different; as a newly emerged business form, cross-border e-commerce imposes certain difficulty for regulations over intellectual property rights of customers department. In order to improve the speed of goods transportation and reducing the occurrence of disputes relevant with goods intellectual property rights, cross-border e-commerce trading platform should take over part of the responsibility and design corresponding regulations according to the features of all stages in intellectual property rights regulation to ensure that resources of goods are in line with the national law, making the customers assured and improving the credibility of cross-border e-commerce trading platforms. 


\section{Need of Further Developing Model Innovation}

As the main site or channel for domestic cross-border e-commerce trading, competition between platforms is becoming increasingly obvious with the continuous expense of market scale in China. Parts of domestic enterprises dedicated in cross-border e-commerce trading platforms have opened domestic direct mail business. It can be seen from this that the working model of cross-border e-commerce trading platforms should be innovated rapidly and the platforms should be further developed from many aspects.

\section{Conclusion}

Construction of cross-border e-commerce trading platform indicates that cross-border trading has entered a new era and many domestic enterprises begin to realize the vast development space in overseas market and gradually become involved in cross-border e-commerce trading platforms. However, with the changes of relevant theoretical knowledge and the situation, many problems are gradually emerging and if those problems are not addressed properly, development of cross-border e-commerce trading platform will be definitely affected.

\section{Acknowledgements}

Scientific research fund project: 2015 department of education project in shaanxi province (project number: 15 jk2135).

\section{References}

[1] L. Shi. Digital Protection of Motion-capture Technology over Intangible Cultural Heritage Dance. Yunnan Art Institute, 2015.

[2] K.L. Xiao. Digital Virtual Application of Folk Drama Art. Art Education Research. 2015, 16: 38-39.

[3] X.Y. Liu. On the "Cross-border" Factors of Cross-border E-commerce Development in China. Lanzhou Institute of Education, 2015, 02: 44-45 + 164.

[4] P. Yu. Dance Comment of Shape Analysis - Career Orientation of Dance Comment in a New Era (Second Part) . Beijing Dance Institute, 2015, 02: 1-28.

[5] C.X. Zhang, Z. Wu. On the Basic Features and Development Trends of Dance Animation . Beijing Dance Institute, 2007, 02: 110-113.

[6] H. Cao. On Several Issues in the E-commerce Development Strategy of Traditional Enterprises in China. Internet Week, 2014,11: 18-27.

[7] J.Z. Yang, L. Yu. Analysis on the Application of Cross-border E-commerce in Foreign Trade Enterprises in China. Contemporary Economic Management, 2014,06: 58-63.

[8] C.L. Qi. Transformation of the Operation Mode in Foreign Trade Enterprises in China Promoted by Cross-border E-commerce. Chinese commerce, 2014,16: 160-162. 